\title{
Vascularized nerve "grafts": just a graft or a worthwhile procedure?
}

\section{Salvatore D'Arpa, Karel Etienne Yvonne Claes, Filip Stillaert, Britt Colebunders, Stan Monstrey, Phillip Blondeel}

Department of Plastic and Reconstructive Surgery, University Hospital Ghent, 9000 Ghent, Belgium.

Address for correspondence: Dr. Salvatore D'Arpa, Department of Plastic and Reconstructive Surgery, University Hospital Ghent, 9000 Ghent, Belgium. E-mail: salvatore.darpa@uzgent.be

\begin{abstract}
The aim of this review is to extrapolate evidence regarding the use of vascularized nerve grafts (VNGs) in peripheral nerve reconstruction and summarize available data on their indications, if any, and clinical applications. A review of the literature via the PubMed database was performed with analysis of ninety-five articles on the experimental and clinical studies of VNGs. Eight relevant questions were selected to be answered about VNGs. VNGs allow faster nerve regeneration and convey a functional advantage under certain clinical conditions such as large nerves, proximal lesions, and nonvascularized recipient beds. Several donor sites are available which have been being divided by body region in this manuscript. VNGs perform better than non-VNGs and provide an advantage in selected cases. However, limited availability and donor site morbidity still limit their application. We foresee a wider application of vascularized nerve allografts to overcome these problems.
\end{abstract}

Key words:

Nerve injury, nerve reconstruction, nonvascularized nerve graft, vascularized nerve graft

\section{INTRODUCTION}

The first nerve graft was performed by Phillipeaux and Vulpian in $1870 .^{[1]}$ In 1939, Bunnel and Boyes ${ }^{[2]}$ reported their experience with thin autogenous nerve grafts, which were transplanted with encouraging results. Soon thereafter, the clinical outcomes of free autologous nerve grafting were improved by the application of cable grafts to improve graft revascularization and avoid the central necrosis observed in large grafts. ${ }^{\mid 3-5]}$

To overcome the problems caused by central necrosis due to insufficient vascularization observed with nonvascularized nerve grafts (NVNGs), ${ }^{[5]}$ VNGs were introduced as a solution to improve nerve graft outcomes.

The first VNG in the upper extremity was a pedicled nerve graft, described in 1945 by St. Clair Strange. ${ }^{[6]}$

\begin{tabular}{|l|l|}
\hline \multicolumn{2}{|c|}{ Access this article online } \\
\hline Quick Response Code: & Website: \\
\hline & www.parjournal.net \\
\hline & \\
\hline & \\
\hline
\end{tabular}

In 1976, Taylor and $\mathrm{Ham}^{[7]}$ reported the first free VNG: a $24 \mathrm{~cm}$ segment of the superficial radial nerve, based on the radial artery, was used to reconstruct a median nerve in a case of Volkmann's ischemic contracture. Since then, several experimental and clinical studies have investigated the role and effectiveness of VNGs although conclusive findings have not been reported. The fact itself that VNGs are still named "grafts" instead of "flaps" testifies the doubts surrounding the benefits of a vascularized nerve repairing a nerve gap.

Although it is generally believed that VNGs perform better for longer gaps and larger nerves or in scarred beds, evidence is lacking. Whether a more complicated VNG procedure is justified or not, and when, is still unclear.

We have performed a review of the literature of both experimental and clinical studies on VNGs to find answers to the following questions:

- What is the theoretical advantage of a VNG?

- Do VNGs have an efficient vascularization?

- Is vascularization of a VNG superior to that of a NVNG?

- Regeneration in VNGs vs. NVNG

- What are the indications for a VNG?

- Comparison of donor sites in the upper and lower limbs

- How should we consider the nerve incorporated in a flap? 


\section{WHAT IS THE THEORETICAL ADVANTAGE OF A VASCULARIZED NERVE GRAFT?}

A VNG should be theoretically result in a more functional nerve for several reasons: (1) vascularization is maintained: revascularization of the nerve graft restores the extrinsic neural blood vessels; (2) reduction of intraneural fibrosis secondary to ischemia facilitates axonal regeneration; (3) faster reinnervation reduces denervation muscle atrophy; and (4) maintenance of vascularization promotes faster Wallerian degeneration and clearance of myelin debris, reducing obstruction to axonal growth into the graft with faster remyelination of regenerated axons.

Nerves have both an extrinsic and intrinsic blood supply. The extrinsic system consists of arteries and veins that accompany a nerve outside of its epineurium for a variable distance along its length. The intrinsic system consists of epineural, perineural and endoneural vessels running longitudinally within the nerve. The two systems freely interface through the vasa nervorum, which pass through the mesoneurium.

Conventionally, interpositional nerve grafting interrupts both the extrinsic and intrinsic systems, which can be restored only by peripheral neovascularization. Lind and Wood $^{[8]}$ suggested that early ischemia of conventional nerve grafts may be associated with sufficient graft necrosis to hinder the stromal function of the graft as a conduit for advancing axons.

Revascularization of a nerve graft is carried out in two ways: vessels from the surrounding tissue bed grow into the graft tissue (centripetal revascularization) and vessels from the end of the graft sprout into the existing vascular tree (inosculation). Vascular ingrowth from the surrounding tissues is the most important. ${ }^{[8,9]}$ As donor nerve caliber increases, the ability for neovascularization to reach the center of the nerve decreases. ${ }^{[2,5]}$ Experimental and clinical evidence have confirmed that a critical diameter is reached beyond which central necrosis will result. ${ }^{[10-12]}$

\section{DOVNGs HAVE AN EFFICIENT VASCULARIZATION?}

Several clinical and experimental studies have demonstrated that free and pedicled VNGs do have an efficient vascularization, that their extremities bleed well after isolation and transfer, that they are well-perfused and that their anastomoses stay patent. ${ }^{[13]}$

It has been postulated that VNGs can be performed without the need for venous anastomosis because they drain through their cut ends. El-Barrany et al. ${ }^{[14]}$ have described five types of nerve vascularization patterns in relation to their feasibility for harvest as VNGs: (1) no dominant arterial pedicle; (2) one dominant arterial pedicle; (3) one dominant arterial pedicle that divides into two branches which course along the nerve; (4) multiple dominant arterial pedicles; and (5) multiple dominant arterial pedicles which form a continuous artery accompanying the nerve.

According to the authors, the best nerves for use as VNGs are the superficial radial nerve and the deep peroneal nerve (type 2 grafts), the saphenous nerve (type 4 graft) and the ulnar nerve (type 5 graft). ${ }^{[14]}$

Taylor and $\mathrm{Ham}^{[7]}$ also classified peripheral nerves according to their blood supply with special reference to their suitability for microvascular free transfer:

(1) Type A: considered to be the ideal nerve for free transfer, as the neurovascular bundle contains a long unbranched nerve that receives a segmental blood supply from a single parallel arteriovenous (AV) system. The superficial radial and ulnar neurovascular bundles, the posterior and anterior tibial neurovascular bundles and the median nerve with the brachial artery belong to this type; (2) Type B: similar to Type A, but the nerve branches early and must be reversed to avoid axonal loss, provided that the unidirectional flow of the veins is taken into account. The intercostal neurovascular bundle or the radial nerve with the profunda brachii artery belong to this type; (3) Type C: long unbranched nerve supplied by a single large nutrient vessel; the median nerve when supplied by a large median artery or the sciatic nerve when its arteria comitans is the dominant supply belong to this type; (4) Type D: long unbranched nerve which receives nutrient branches from different "parent" vessels of various diameters. The sciatic nerve in the thigh belongs to this type. Conversely, the sural nerve and the meodial cutaneous nerve of the forearm are usually unsuitable, as the "parent" vessels which give rise to the nutrient branches are small and diverse; and (5) Type E: branching nerve with a fragmented blood supply; a most unsatisfactory situation for free transfer. The posterior cutaneous nerve of the forearm, the cutaneous nerves of the thigh, and the saphenous nerve in the calf belong to this type.

\section{IS VASCULARIZATION OF A VNG SUPERIOR TO THAT OF A NVNG?}

Yes, vascularization of a VNG is considered to be superior as it possesses an independent blood supply that avoids ischemia eliminating the need for revascularization from the surrounding wound bed. It is speculated that this avoids core necrosis and eventual scarring within the graft and maintains Schwann cells viability. ${ }^{[7]}$

Although it has been shown that VNGs are efficiently vascularized, it can be postulated that revascularization of a NVNG can, under certain conditions, be as efficient as a well-vascularized bed. NVNG remain nonvascularized for 3 days in a well-vascularized bed ${ }^{[15]}$ and for up to 14 days in a nonvascularized bed. ${ }^{[16]}$ The flow across NVNG then catches up and is even superior to that of VNG. ${ }^{[17]}$ This difference can be explained by the flow 
modifications observed in a pedicled flap ${ }^{[18]}$ such as sympathetic stimulation that reduces blood flow to 93\% of normal through production of noradrenaline, vasoactive intestinal polypeptide, 5-hydroxytryptamine and substance P. Most experimental models assessed pedicled VNG affected by these factors, rather than free ones. ${ }^{[19,20]}$ Settergren and Wood. ${ }^{[17]}$ showed in their canine model a better blood flow after 4-6 days for NVNG compared to a VNG. A free VNG, not affected by sympathetic stimulation, would likely eliminate this difference.

While NVNGs, when placed in a well-vascularized bed, undergo a $72 \mathrm{~h}$ period of warm ischemia prior to neovascularization, VNGs do not. ${ }^{[16,17]}$ When placed in a nonvascularized bed, the ischemic period last up to 14 days for a short NVNG (30 mm nerve graft in rats), ${ }^{[16]}$ while VNGs have no ischemia time. Despite remaining avascular for 14 days, NVNGs eventually regained their vascularity and performed better than VNGs on nerve conduction velocity studies. ${ }^{[16,17]}$ Still it is unclear if this has any clinical relevance.

The above findings were observed in thin small animal nerves. It is likely that a larger nerve, such as a human mixed nerve of a limb, is not as efficiently revascularized from the surrounding bed as the small nerves investigated in animal models. Clinical experience has shown that small cable grafts are required to make a large caliber nerve that will be efficiently revascularized. ${ }^{[10-12]}$ Revascularization might not reach the core in a NVNG while a VNG stays well-perfused.

\section{REGENERATION IN VASCULARIZED NERVE GRAFTS VERSUS NONVASCU-LARIZED NERVE GRAFT}

Although the mechanism is not clear, VNGs appear to provide more effective regeneration than NVNGs. This difference becomes more evident and functionally relevant as length and caliber of the graft increase and as wound vascularization decreases. No comparison has been made in the clinical setting, but clinical reports generally agree that VNGs provide faster regeneration.

Studies of VNGs in animal models have reported conflicting results. For the purpose of clarity, we have divided the following discussion into studies performed on a vascularized bed and studies performed on a nonvascularized bed.

\section{Normal (vascularized) bed}

McCullough et al. ${ }^{[21]}$ found no difference between vascularized and nonvascularized grafts when studied by electrophysiological examination and the degree of axonal regeneration. In a similar rat sciatic nerve model, Seckel et al. ${ }^{[22]}$ found no differences in number of regenerated axonal fibers, amount of intraneural scarring, or thickness of regenerated myelin sheaths. Pho et al. ${ }^{[23]}$ performed histological studies in eighteen rat femoral nerves. Their experiment showed no difference in the degree of vascularization, reticulin framework collapse, rate and extent of axonal regeneration and remyelination between non-vascularized and conventional nerve grafts.

In contrast, using a large sciatic nerve gap in the rabbit, Restepo et al..$^{[24]}$ found that VNGs in all time periods studied (from 5 weeks to 15 weeks) did better in terms of remyelination and number of axonal fibers than did conventional nerve grafts. Shibata et al. ${ }^{[25]}$ reported results on 40 rabbits median nerve grafts (20 vascularized and 20 nonvascularized). Although there were no significant differences in nerve conduction, action potential, and axon diameters, there were statistically significant differences in muscle contraction force $(20 \%$ greater in VNGs than NVNGs and comparable to the healthy control side) and axon counts. Kanaya et al. ${ }^{[26]}$ reported that the vascularized sciatic nerve graft group showed a better mean sciatic function index $(\mathrm{SFI})^{[27]}(n=30$, SFI $=-64 \pm 11)$ than the nonvascularized sciatic nerve graft group $(n=27$, $\mathrm{SF}=99 \pm 7)(P<0.01)$. A SFI of -100 represents a complete loss of function of the nerve. There was also a significantly higher nerve conduction velocity in the VNG group. This was the only study to evaluate the resulting function instead of morphologic parameters. In a normally vascularized bed, VNGs appear to perform better. Kärcher and Kleinert ${ }^{[28]}$ evaluated recovery following a $1.5 \mathrm{~cm}$ sciatic nerve defect in rats repaired with a pedicled femoral nerve graft with the creation of an AV fistula of the femoral vessels. He reported better and faster regeneration of a VNG that was complete at 5 months, but which was incomplete in the NVNG.

\section{Scarred (nonvascularized) wound bed}

Koshima and Harii ${ }^{[29]}$ tried to replicate a scarred wound bed using a rat burn wound model with nerves transplanted into silicone tubes. They demonstrated an increased size and density of myelinated axons and earlier regeneration of nerve fibers in VNGs as compared to conventional nerve grafting.

Mani et al. ${ }^{[16]}$ did not find any significant difference in nerve conduction velocity studies between vascularized and non-VNGs in avascular graft beds, even following a prolonged initial period of revascularization for non-VNGs.

\section{Functional results}

Prior studies have produced conflicting results secondary to a lack of homogeneity in evaluation methods. As previously noted, Kanaya et al. ${ }^{[26]}$ reported in their work that the vascularized sciatic nerve graft group showed a significantly better mean SFI ${ }^{[27]}$ than the nonvascularized sciatic nerve graft group.

Several authors had reported superior results when placing VNGs where previous conventional nerve grafts had already failed. Rose and Kowalski ${ }^{[30]}$ reported good results with the dorsalis pedis artery-peroneal nerve complex in five cases with a digital sensory nerve reconstruction in the setting of prior failed non-VNGs. 
Other clinical studies have suggested that VNGs perform better in poorly vascularized, ${ }^{[7,31]}$ scarred beds. ${ }^{[32-35]}$

\section{WHAT ARE THE INDICATIONS FOR A VNG?}

It is impossible to establish clear-cut indications for VNGs, as experimental settings fail to replicate actual clinical situations. Having established that VNGs perform better than NVNGs under specific conditions, the clinical papers available were reviewed. The currently available literature provides only case reports or case series where the indication is based on the surgeon's judgment and experience, rather than on experimental findings. However, the surgeon's judgment and experience are also worthy. The current indications for VNG are presented, divided into zone of injury.

Vascularized nerve grafts are not indicated in all nerve reconstruction procedures. When a NVNG works well, the additional complexity, and sometimes morbidity, of the procedure is not justified by superior results. A VNG must be considered in the following scenarios [Table 1]: (1) nerve gaps longer than $6 \mathrm{~cm}$. This is an arbitrary and linear measure that does not take into the account the diameter of the nerve to be reconstructed. However, the diameter can be increased with cable grafting; (2) nonvascularized beds; (3) composite defects requiring a free flap. In these cases, the nerve can be included in the free flap with little complexity and no morbidity using the same donor site and the nerves directed to the flap; (4) proximal lesions (brachial plexus); (5) long denervation times. The faster reinnervation provided by a VNG might be an advantage in cases that have been referred late and in which muscle atrophy has ensued; (6) cases that have to undergo radiation therapy which could compromise or retard the rate of revascularization; and (7) presence of an available donor nerve in the same surgical field which can be harvested without additional morbidity, such as the pedicled great auricular nerve in facial nerve defects during parotidectomies.

Age is a controversial issue as regeneration is worse with aging, but a more complex procedure might also be less desirable in the elderly. Because recovery is slower with age, it might be a relative indication for a VNG. However, age alone is not a contraindication to a microsurgical procedure, and aged people in good general condition can be considered candidates for a VNG. This applies especially to motor nerves reconstruction and to late referrals.

In the following sections, clinical indications will be reviewed divided by anatomical region in order to provide a quick reference to those who approach VNG nerve reconstruction.

\section{Facial nerve injuries}

Since Balance and Duel| ${ }^{[36]}$ first introduced nerve grafting for the bridging of facial nerve defects, the sural nerve, the ansa cervicalis, and the great auricular nerve have been the most commonly used NVNGs. ${ }^{[37]}$ In scarred, irradiated, or to be irradiated fields, functional recovery of the facial nerve can be less satisfactory and VNGs have been used for cases with these risk factors. ${ }^{[38-41]}$ Although these reports are anecdotal without comparison to NVNGs, there appears to be a consensus for this indication $^{[42]}$ [Table 2].

The VNGs used are:

\section{Vascularized great auricular nerve graft}

Koshima et al. ${ }^{[4]}$ used a pedicled $4 \mathrm{~cm}$ vascularized ipsilateral great auricular nerve graft for the buccal branch and a nonvascularized sural nerve graft for the zygomatic branch to provide an intrapatient control. They reported faster and better recovery for the VNG.

\section{Vascularized lateral femoral cutaneous nerve graft}

The lateral femoral cutaneous nerve (LFCN) can be harvested with an anterolateral thigh (ALT) flap, with a superficial circumflex iliac artery perforator (SCIP) flap or alone. ${ }^{[40]}$ Lida et al. ${ }^{[43]}$ reported the first successful use of a free vascularized LFCN graft combined with an ALT flap to repair the facial nerve and a soft tissue defect, and provided objective measurements of functional recovery at 14 months (House-Brackmann ${ }^{[4]}$ grade III/NI, 40-point grading system: ${ }^{(45]} 28 / 40$ ). Kashiwa and colleagues described an inferolateral extension of the groin flap based on the vessels accompanying the $\mathrm{LFCN}^{[46]}$ for reconstruction of a facial skin and soft tissue defect including all branches of the facial nerve following tumor ablation with nerve gaps of up to $10 \mathrm{~cm}$. The authors did not report any objective data but noted that facial animation began to return 6 months postoperatively, even in the setting of postoperative chemotherapy and radiotherapy. They observed that a relatively "comfortable" result was obtained, aside from some degree of synkinesis due to misdirection of the regenerated nerve.

\section{Table 1: Indications for VNGs}

\section{Nerve gaps longer than $6 \mathrm{~cm}$}

Nonvascularized beds

Composite defects requiring a free flap

Proximal lesions (brachial plexus)

Long denervation times

Planned radiation therapy

Pedicled VNG available in the same field

Advanced age

VNG: Vascularized nerve graft

Table 2: Indications for a VNG in facial nerve injuries

Vascularized great auricular nerve

Vascularized LFCN

Vascularized deep peroneal nerve

Vascularized sural nerve

Vascularized motor nerve of the vastus lateralis muscle

Fascicular turnover method

VNG: Vascularized nerve grafts, LFCN: Lateral femoral cutaneous nerve 
There are three shortcomings of this method. First, the location and direction of the nerve graft are restricted because the nerve graft is attached to the ALT flap. Therefore, a sufficient length of the nerve graft is required, theoretically increasing time to reinnervation. Second, the number of branches of the LFCN varies greatly among patients. In cases in which the number of branches is fewer than that required for facial nerve reconstruction, an additional free nerve graft is needed. Finally, if the recipient nerve is larger than the lateral femoral nerve branches and the nerve has to be cable grafted, vascularization will be interrupted, resulting in a mixed VNG/NVNG reconstruction.

\section{Vascularized deep peroneal nerve graft}

Koshima et al..$^{[39]}$ reported a case in which a combined anteroposterior tibial perforator-based flap was used for the repair of a large facial defect involving the facial nerve (10 cm nerve gap). The deep peroneal nerve of the flap was interposed between the proximal stump and the transected zygomatic and buccal branches of the facial nerve. The authors reported the subjective judgment of a "considerable degree of facial animation" on the affected side eighteen months postoperatively. The disadvantages of this VNG are temporary postoperative edema, hypoesthesia of the donor foot and a poor donor site scar where skin has been harvested.

\section{Deep peroneal, sural and vastus nerves}

Kimata et al..$^{[38]}$ reported 10 cases of facial nerve reconstruction in which several types of VNGs were used for reconstruction of multiple branches of the facial nerve. The nerves used were: (1) the free vascularized sural nerve graft, attached to a small peroneal monitoring flap and nourished by the peroneal vessels; (2) the free vascularized deep peroneal nerve graft attached to a small dorsalis pedis monitoring flap and nourished by anterior tibial vessels; (3) the free vascularized motor nerve of the vastus lateralis muscle nourished by the descending branch of the lateral circumflex femoral vessels; and (4) the free vascularized lateral femoral nerve of the thigh combined with an ALT flap.

In 4 patients, the functional recovery of the facial nerve could not be assessed because of local tumor recurrence soon after surgery. Results with the House-Brackmann system $^{[44]}$ were grade II in 1 patient (vascularized sural nerve), grade III in 4 patients (three vascularized deep peroneal nerves and one vascularized motor nerve of the vastus lateralis), and grade IV in 1 patient (vascularized sural nerve). Results with the 40-point system ${ }^{[45]}$ ranged from 20 to 28 points (mean score, 23 points). No control was provided.

\section{Fascicular turnover method}

Koshima et al. ${ }^{[47]}$ described the "fascicular turnover method", in which a vascularized fascicular flap was used for repairing nerve gaps. A $3 \mathrm{~cm}$ facial nerve gap was repaired with this technique with preservation of the zygomatic and marginal mandibular branches. The distal portion of the main buccal branch had three fascicles. Therefore, a fascicular turnover flap from the distal buccal branch was elevated to reconnect the nerve gap without tension. The paralyzed major zygomatic muscle became active three months later. No control was provided.

When a single branch is compromised, the pedicled great auricular nerve is an option that causes no additional morbidity and which can be used with minimal additional effort.

The best method for repair of multiple branches of the facial nerve appears to be the LFCN graft without an ALT component that restricts motion. Should the skin or adipose tissue component of the ALT be needed together with the nerve to replace soft tissues, the best solution is harvest as a chimera, based on a different perforator than that nourishing the nerve, thus avoiding restrictions in nerve movement and allowing better inset. The branching of the nerve allows repair of up to three branches with adequate length and similar caliber. Using it with the ALT or SCIP requires an exceedingly long graft and limits motion. An alternative for the reconstruction of all five branches, which to our knowledge has not yet been utilized, is the long thoracic nerve. ${ }^{[48]}$

\section{Upper limb}

Injuries to the ulnar nerve are the most frequent, occurring either in isolation or in association with the median nerve. ${ }^{[49,50]}$ These injuries, when compared to radial and median nerve injuries, are believed to have the least favorable outcome among nerve injuries in the upper extremity. ${ }^{[51-54]}$ Ulnar nerve injuries are the most common at the wrist, forearm, or elbow, secondary to trauma or entrapment.

Recovery of intrinsic muscles function is more important than sensory restoration. ${ }^{[10]}$ In their meta-analysis, Ruijs et al. ${ }^{[52]}$ reported that the chance of motor recovery in ulnar nerve injuries was $71 \%$ lower than in median nerve injuries. Multivariate logistic regression analysis showed that age, site (intermediate and high showed better results than low lesions), and delay between injury and repair were significant predictors of successful motor recovery. No significant difference was found between median and ulnar nerve injuries regarding sensory recovery. This is supported by other large studies. ${ }^{[53,55]}$ Age and delay between injury and repair were found to be significant predictors for sensory recovery. ${ }^{[52]}$

\section{Vascularized lateral femoral cutaneous nerve graft}

Koshima et al..$^{[40]}$ described a case of a 28-year-old woman with a wide massive tumor resection of the upper arm, which resulted in a soft tissue defect that included $12 \mathrm{~cm}$ long segments of the brachial artery and median nerve. A flow-through ALT flap and vascularized LFCN graft were harvested with separate vascular pedicles. Tinel's sign reached the wrist joint 6 months after surgery. Two and a half years postoperatively, moving 2-point discrimination (PD) on the fingers controlled by the 
median nerve was $10 \mathrm{~mm}$. No information is available about motor recovery.

\section{Vascularized sural nerve graft}

The sural nerve was reported initially as a vascularized graft by Gilbert and Fachinelli et al. ${ }^{[56,57]}$ although the dominant vascular pedicle was absent in a high percentage of cases. ${ }^{[58]}$ Fachinelli et al. ${ }^{[57 \mid}$ reported that it receives its extrinsic vascular supply from two distinct sources. Proximally, the cutaneous nerve receives contributions from the superficial sural artery and distally from the musculocutaneous and fasciocutaneous perforators of the posterior tibial and peroneal (fibular) arteries. The medial sural nerve is a good donor for VNGs due to its long length, superficial accessibility, and minimal donor morbidity.

Vascularized sural nerve graft supplied by the superficial sural artery, Riordan et al. ${ }^{[59]}$ reported that the mean percentage of neural tissue within the sural nerve in the region where it is supplied by the superficial sural artery was $62 \%$ compared to $34 \%$ distally, where it was supplied by the posterior tibial and fibular (peroneal) arteries. They reported two clinical cases (right and left arm in the same patient) using the vascularized sural nerve with the superficial sural artery as folded cable grafts for repairing $20 \mathrm{~cm}$ and $12 \mathrm{~cm}$ median nerve defects, respectively. A subjectively evaluated good recovery was reported. No control was provided.

Vascularized sural nerve graft supplied by a muscular branch of the posterior tibial artery: in contrast to Riordan et al., ${ }^{[59]}$ Doi et al. ${ }^{[31,32]}$ stated that the superficial sural artery is unreliable as a nutrient vessel for the sural nerve. They used a vascularized sural nerve graft containing a muscular branch of the posterior tibial artery in 27 cases and compared them to 22 conventional sural nerves.

In 8 axillary nerve repairs (5 free vascularized sural nerve grafts and 3 conventional grafts), there was no statistically significant difference between the mean time to electromyographic reinnervation of the deltoid muscle or the strength of the deltoid muscle 24 months after surgery.

In 7 median nerve defects (4 vascularized sural nerve grafts and 3 conventional nerve grafts), there was a statistically significant difference between the vascularized and the nonvascularized sural nerve grafts in terms of mean speed of advancement of Tinel's sign $(1.8 \mathrm{~mm} / \mathrm{day}$ in the vascularized group vs. $0.5 \mathrm{~mm} / \mathrm{day}$ in the conventional group, $P<0.05$ ), mean time to S2 sensory reinnervation in the fingertip distal to the distal finger crease (16.8 weeks in the vascularized group vs. 30.7 weeks in the conventional group, $P<0.05$ ) and time to electromyographic reinnervation of the abductor pollicis brevis muscle (6-8.5 months, mean: 7.4 months) in the vascularized group vs. 11-14 months (mean: 12.5 months) in the conventional group, $P<0.05)$.

In 7 lower ulnar nerve lesions (4 vascularized and 3 nonvascularized sural nerve grafts), the mean advancement of Tinel's sign 2 months postoperatively $(1.6 \mathrm{~mm} /$ day in the vascularized group vs. $0.6 \mathrm{~mm} / \mathrm{day}$ in the conventional group, $P<0.05$ ), the mean time to S2 sensory recovery in the tip of the small finger (4.3 months in the vascularized group vs. 6.7 months in the conventional group, $P<0.05$ ), and mean time to electromyographic reinnervation of the abductor digiti minimi muscle $(6.25$ months in the vascularized group vs. 8.5 months in the conventional group, $P<0.05$ ) were significantly shorter in the vascularized sural nerve graft group. Functional evaluation 2 years postoperatively was M3.3 ${ }^{|60|}$ S3 and M2, S2 for successful vascularized and conventional grafts, respectively. These differences in function were also statistically significant $(P<0.05)$.

Nine radial nerves (5 high and 4 low lesions) were repaired with 4 vascularized sural nerve grafts and 5 conventional sural nerve grafts. Two high radial nerve injuries were repaired with vascularized grafts, with significantly more rapid mean advancement of Tinel's sign 2 months postoperatively. The mean time to electromyographic reinnervation of the extensor digiti communis muscle in the vascularized group was also significantly faster For low lesions, there was no significant difference in mean time to electromyographic reinnervation to the extensor digiti communis muscle and in final motor evaluation between VNG and NVNG groups.

Thirteen digital nerve defects in the palm were repaired with seven vascularized sural nerve grafts and six conventional sural nerve grafts. The mean advancement of Tinel's sign in the vascularized group was $1.7 \mathrm{~mm} / \mathrm{day}$, whereas the speed in the conventional graft group was $0.5 \mathrm{~mm} /$ day $(P<0.05)$. The final sensory recovery in the two groups was not statistically different.

Vascularized sural nerve graft supplied by the peroneal artery: although the peroneal artery does not directly supply the sural nerve, Hasegawa et al. ${ }^{[42]}$ used the fasciocutaneous perforators of the peroneal artery for sural nerve grafts. When a large nerve gap is accompanied by extensive scarring following severe trauma, soft tissue rich in blood vessels needs to be grafted along with the skin and nerve. Therefore, the authors conserved the blood flow to the sural nerve by harvesting the peroneal artery and vein as a vascular pedicle, along with the fascia and the subcutaneous fat tissue, which has a rich vascular plexus. They reported 6 patients who underwent vascularized sural nerve grafting (five to the median nerve and one to the ulnar nerve) with a monitoring skin flap, one of which failed..$^{\mid 42]}$ The length of the vascularized sural nerve grafts ranged from 20 to $30 \mathrm{~cm}$, with a mean length of $23.3 \mathrm{~cm}$. In the five successful cases, the mean static-2-PD at the corresponding fingertip was $14.2 \mathrm{~mm}$ (range: 10-20 mm). Semmes-Weinstein test findings were filament 6 in 2 patients and filament 10 in 3 patients. The authors concluded that vascularized sural nerve grafting should be considered as a clinical alternative for nerve reconstruction in patients with nerve defects longer than $20 \mathrm{~cm}$. No controls were provided. 
Vascularized sural nerve graft supplied by an arterialized saphenous vein: Townsend and Taylor ${ }^{[33 \mid}$ presented five upper extremity cases in which a composite saphenous vein-sural nerve graft was used for median $(n=3)$ or ulnar nerve $(n=2)$ defect of $6-21 \mathrm{~cm}$ in length. The denervation time was 5 months to 2 years. Their results showed a Tinel's advancement comparable with a primary repair (1 mm/day in 2 cases). In 1 case with reconstruction of the median nerve with a $17 \mathrm{~cm}$ vascularized sural nerve graft, the advancement was 3 times faster.

Gu et al ${ }^{[61]}$ presented the same model of a sural nerve graft based on an arterialized saphenous vein for the repair of median, ulnar, or radial nerves in 14 patients. As expected, the denervation time had a profound influence on final results: 2 patients ( 1 radial nerve injury of $13 \mathrm{~cm}$ and 1 ulnar nerve injury of $10 \mathrm{~cm}$ ) with denervation time of less than 8 months had full restoration of motor function. In contrast, patients operated on after 18 months showed no motor recovery.

\section{Vascularized nerve grafts with vascularized fascia}

Terzis and Kostopoulos ${ }^{[2]}$ reported the results of twenty-one VNGs used for reconstruction of nerve injuries in the upper extremity. Vascularized fascia was used to improve the blood supply of the underlying bed by enveloping the nerve reconstruction. The authors reported satisfactory results although the study lacked a control group.

In case of a nerve injury of the upper limb associated with a soft tissue defect, the surgeon can use a flow-through ALT flap and a vascularized lateral femoral nerve graft. However, inset is difficult, and the nerve should be harvested as proximally as possible in order to obtain a larger caliber. To match the recipient nerve caliber, using cables from the donor as a NVNG may be necessary [Table 3].

When there is only a nerve injury for which a VNG is indicated, we advise using a vascularized sural nerve graft as there will be less caliber mismatch.

\section{Brachial plexus injuries}

\section{Vascularized ulnar nerve graft}

The vascularized ulnar nerve trunk graft can be used as a free microsurgical transfer or pedicled on the superior collateral ulnar artery. ${ }^{[63]}$

Chuang et al ${ }^{[64]}$ reported results of 167 patients who were treated for impaired elbow flexion caused by brachial plexus injury. Ruptured plexus injuries recovered better than root avulsions and infraclavicular plexus injuries performed better than supraclavicular injuries. Functional results revealed that nerve reconstruction produced results superior to muscle tendon transfers. The authors also found that vascularized ulnar nerve grafts were

Table 3: Indications for the upper limb nerve injury

Vascularized LFCN

Vascularized sural nerve

VNG with vascularized fascia

LFCN: Lateral femoral cutaneous nerve, VNG: Vascularized nerve grafts superior to conventional long nerve grafts $(12 / 15$ patients or $80 \%$ success rate vs. $18 / 27$ patients or $66 \%$ success rate). A pedicled VNG was more reliable than a free VNG for the reconstruction of elbow flexion; of the 9 patients who had a pedicled vascularized ulnar nerve graft, eight achieved a muscle grade greater than M3. However, of 6 patients with free vascularized ulnar nerve graft, only four achieved a grade greater than M3.

Terzis and Kostopoulos ${ }^{[65]}$ reported 151 reconstructions with ulnar nerves performed in 67 patients for brachial plexus injuries. Patients were divided into 4 groups: (1) pedicled vascularized ulnar nerve graft from ipsilateral donors, (2) free vascularized ulnar nerve graft from ipsilateral donors, (3) vascularized ulnar nerve graft from contralateral donors to the median nerve, and (4) vascularized ulnar nerve graft from contralateral donors to single motor targets (e.g. axillary, musculocutaneous and triceps) $(n=25,21,13$, and 8 respectively). Postoperative muscle strength for patients who were operated on late (denervation time $>12$ months) was significantly decreased compared with the early group $(<6$ months) $(P=0.049)$. The vascularized ulnar nerve grafts for median nerve neurotization also yielded protective sensation in the hand in $91.6 \%$ of the patients and produced better outcomes when compared to conventional nerve grafts (51\% protective sensation). ${ }^{[66]}$ The authors concluded that, although VNGs can enhance the speed of regeneration, factors such as patient age (better results for younger patients), denervation time (poor results for late patient presentation), and graft length (better results for ipsilateral grafting) do influence the results.

Birch et al. ${ }^{|67|}$ reported 42 brachial plexus lesions that were reconstructed with a vascularized ulnar nerve graft (33 based on the ulnar vessel and 9 based on collateral vessels in the arm). Of the 42 patients, 33 patients regained functional elbow flexion after connecting the C5 root to the lateral cord or to the musculocutaneous nerve, using a free ulnar nerve graft shorter than $18 \mathrm{~cm}$. Significant functional recovery of the hand occurred in only 1 patient. In 10 patients, recovery into the flexors of the wrist and/or the digits reached grade 3 power, but function was restricted to only a hook grasp. Sensory return sufficient for recognition of harmful stimuli and temperature change occurred in 10 patients. Delay from injury to operation had a significant bearing on the outcome: 4 patients with grafts performed more than 6 months following injury and 6 of 23 patients operated upon between 2 and 6 months did not achieve any functional recovery. These positive results match those of Oberlin et al.. ${ }^{\mid 68]}$ who also used free vascularized ulnar nerve grafts. The grafts had a length between 8 and $25 \mathrm{~cm}$ (mean: $13.5 \mathrm{~cm}$ ). In $83 \%$ of the 18 cases, there was a functional return of elbow flexion.

Bertelli and Ghizoni[69] reported on results obtained with the reconstruction of elbow flexion. They used pedicled ulnar nerve grafts, averaging $30 \mathrm{~cm}$ of length, with which they connected the $\mathrm{C} 5$ root to the musculocutaneous nerve. None of the patients recovered useful function 
mediated by the vascularized ulnar nerve, and none scored higher than M2 for either elbow flexion or wrist extension. These results may have been influenced by the delay to surgery, which occurred between 3 and 7 months after the injury.

\section{Vascularized intercostal nerve transfers}

Okinaga and Nagano ${ }^{[70]}$ compared nonvascularized $(n=6)$ with vascularized $(n=5)$ intercostal nerve transfers in patients with brachial plexus injuries. There were no statistically significant differences in (1) the time to appearance of a Tinel's sign, which radiated to the chest wall on the upper arm after surgery; (2) the rate of advancement of a Tinel's sign between the upper arm and the wrist; (3) the time interval between surgery and initiation of reinnervation as demonstrated by needle electromyography; (4) the strength of elbow flexion at the final examination according to the Medical Research Council's grading system; and (5) the strength of elbow flexion at the final examination as measured by a potentiometer held on the wrist at an angle of $100^{\circ}$ of flexion. It is likely that statistical significance was not reached due to the small sample size.

Because most clinical evidence is in favor of the ipsilateral vascularized ulnar nerve trunk graft, we advise its use for reconstruction of a brachial plexus injury. We could not find evidence in favor of either the pedicled nerve graft or the free VNG [Table 4].

\section{Hand}

Vascularized deep peroneal nerve

Vascularized deep peroneal nerve supplied by a dorsalis pedis artery: Rose and Kowalski ${ }^{[30]}$ reported five cases with good results when reconstructing digital nerves in scarred tissue without a concomitant soft tissue defect by means of vascularized deep peroneal nerve segments. They concluded that the deep peroneal nerve-dorsalis pedis artery complex on the dorsum of the foot is an ideal donor site for segmental VNGs in digital sensory nerve reconstruction. Donor morbidity was negligible except for a neuroma in one case and slight superficial skin loss in another.

Koshima et al. ${ }^{[71]}$ reported one case of a deep peroneal VNG with skin from the first web space for reconstruction of a neurocutaneous defect in the finger. This technique has several drawbacks: the skin-grafted web can be a source of major morbidity, ${ }^{[72,73]}$ the skin flap does not adhere to the bone, and during grasping and gripping it will be unstable. Anatomic variations are quite common at the level of the first web space, and the nerve can travel far from the nutrient vessels, ${ }^{[7,75]}$ rendering the flap unusable. ${ }^{[76]}$

Reversed venous arterialized deep peroneal nerve graft: influenced by the works of Townsend and Taylor ${ }^{[33]}$ and $\mathrm{Gu}$ et $a .^{[61]}$ on reversed venous arterialized nerve grafts, Rose et al..$^{[34]}$ investigated the deep peroneal nerve-dorsalis pedis venae comitantes system. Ten adult patients received a total of 14 VNGs. Mean moving 2-PD was $5.8 \mathrm{~mm}$, and static 2-PD was $8.3 \mathrm{~mm}$. The median of Semmes-Weinstein monofilament measurements was $2.83 \mathrm{~mm}$. In 3 digits, a vascularized and a nonvascularized nerve were used for adjacent digital nerve replacement in the same finger. The 3 "reversed venous" grafted nerves recovered with a mean moving 2-PD of $6.7 \mathrm{~mm}$ and a static 2-PD of $9.3 \mathrm{~mm}$. By contrast, the conventional grafts returned moving 2-PD of $10.3 \mathrm{~mm}$ and static $2-\mathrm{PD}$ of $14.3 \mathrm{~mm}$.

\section{Fascicular turnover method}

Koshima et al..$^{[47]}$ believe that, in cases with a digital nerve gap of less than $20 \mathrm{~mm}$ in length, a fascicular turnover flap from either the distal or proximal stump is the best option. However, in cases with nerve gaps measuring over $20 \mathrm{~mm}$, fascicular turnover flaps from bilateral distal and proximal stumps are preferred to connect to the middle portion of the nerve gap, as excellent blood flow of bilateral short flaps can be expected rather than from an ipsilateral longer nerve flap.

Nerve reconstructions in the hand, when a VNG is indicated, appear to be better served by a deep peroneal nerve graft. However, a vascularized lateral femoral nerve graft may also be a useful tool, especially in multiple nerve injuries [Table 5].

\section{Lower limb}

Lower extremity nerve injuries are relatively less common than those of the upper extremities. ${ }^{[10,77]}$ The peroneal nerve is more susceptible to injury than the posterior tibial nerve given its superficial course over the neck of the fibula, where it is relatively fixed with less interfascicular connective tissue. ${ }^{[78,79]}$ Initial outcomes of peroneal nerve reconstruction were poor ${ }^{[77]}$ and the value of attempted repair of the peroneal nerve has been questioned. ${ }^{[80]}$ Although recent studies are more encouraging, the functional recovery of the peroneal nerve (muscle grade more than three) is still low, between $14 \%$ for grafts and $75 \%$ for neurolysis. Results are dependent upon the timing of surgical repair, the graft length, and the level of the injury.

Taylor's group reexamined the blood supply of each lower limb nerve and assessed the potential of each segment of each nerve for vascularized transfer. ${ }^{[81]} \mathrm{VNG}$ and vascularized posterior calf fascia (VPCF) have been used to improve vascularization of the recipient bed and to minimize postoperative scar formation. When a VNG was required for reconstruction of a lower extremity nerve injury, the sural nerve was used, harvested as a pedicled nerve graft based on the superficial sural artery, or as an arterialized venous nerve graft based on the lesser saphenous vein. A concomitant VPCF can be used to improve vascularization.

Table 4: Indications for brachial plexus injuries Vascularized ulnar nerve

Vascularized intercostal nerve

Table 5: Indications for a nerve injury in the hand

Vascularized deep peroneal nerve supplied by a dorsalis pedis artery Reversed venous arterialized deep peroneal nerve graft Fascicular turnover method 
Terzis and Kostopoulos ${ }^{[82]}$ reported 14 lower extremity nerve injuries in 12 patients that had been reconstructed with VNGs. The common peroneal nerve (CPN) was injured in 12 patients and the posterior tibial nerve in 5 patients. The repair of CPN lesions was not recommended given the poor prognosis following nerve reconstruction. ${ }^{\text {[77,83] }}$ The vascularized sural nerve graft was used as a pedicled nerve graft based on the superficial sural artery or as an arterialized-venous nerve graft based on the lesser saphenous vein. Kim and Kline found that good functional recovery could not be expected with a graft length greater than $12 \mathrm{~cm} \cdot{ }^{[84]}$ It has been reported that in the lower extremity all patients with nerve grafts greater than $6 \mathrm{~cm}$ in length had fair or poor results. ${ }^{[79]}$ Grade 3 function was recovered in $38 \%$ of patients with grafts 6-12 cm and in only $16 \%$ of patients with graft lengths of $13-24 \mathrm{~cm} .{ }^{[85]}$ In contrast, with VNGs of $13 \mathrm{~cm}$ or more, grade 3 function was recovered in $66.67 \%$ of patients. Terzis and Kostopoulos ${ }^{[82]}$ showed statistically significant differences $(P=0.008)$ for CPN injuries between patients who underwent surgery within 6 months from the time of injury and patients who presented later than 6 months. Preoperative and postoperative differences in dorsiflexor muscle strength were statistically significant $(P<0.001)$. A correlation between outcome and type of injury and between outcome and age was not found.

In lower extremity nerve injuries, when a VNG is indicated, the best choice is the sural nerve, either as a pedicled nerve graft based on the superficial sural artery and or as an arterialized venous nerve graft based on the lesser saphenous vein [Table 6].

\section{Vascularized nerve allografting}

The use of nerve autografts is limited by the availability of suitable donor sites. Allografting in reconstructive surgery has became more promising with advances in immunosuppression therapy. ${ }^{[86]}$ Mackinnon et al. ${ }^{[87]}$ have pioneered the technique of nerve allografting with encouraging results. Vascularized nerve allografts offer several theoretical advantages: (1) they allow en bloc reconstruction of nerve plexi; (2) they enhance the rate of nerve regeneration; and (3) they permit the use of larger "trunk" grafts without central necrosis. ${ }^{[88]}$

Mackinnon et al. ${ }^{[89,90]}$ described 7 cases of traumatic extremity injuries with massive peripheral nerve deficits that could not be reconstructed by conventional means. Four upper extremities and 3 lower extremities were reconstructed. Nerve allografts were either used exclusively for the reconstruction (2/7) or in combination with autografts (5/7). Total allograft lengths varied from $72 \mathrm{~cm}$ in a 3-year-old patient to $350 \mathrm{~cm}$ for a three-nerve reconstruction in a 16-year-old patient. Initially, the allografts were harvested fresh and used immediately. In subsequent cases, the allografts were temporarily stored

Table 6: Indications for a lower limb nerve injury Vascularized sural nerve based on a pedicled superficial sural artery Vascularized sural nerve supplied by an arterialized lesser saphenous vein in University of Wisconsin solution before engraftment. The immunosuppressive regimen in the first 3 patients consisted of triple therapy with cyclosporin A (CsA), Imuran, and prednisone. The subsequent 4 patients were treated with FK506, Imuran, and prednisone. Immunosuppression was withdrawn sequentially, beginning with prednisone. After the Tinel's sign had progressed into the distal segment of the reconstructed nerve, CsA or FK506 was withdrawn. No significant complications secondary to systemic immunosuppression have occurred. Six of the 7 allografts were clinically successful based on the recovery of sensory and/or motor function in the reconstructed distribution. One patient rejected his allograft.

Although some patients have recovered motor function, sensory recovery has been more consistently observed. Similarly, the predominance of superior sensory (temperature and pain) over motor (intrinsic) recovery has been described in hand transplant recipients. It is yet to be determined if this occurs secondary to differential sensory (particularly sympathetic) nerve regeneration, sensory-motor mismatch, or end organ (muscle) lack of receptivity to reinnervation. ${ }^{[88]}$

\section{COMPARISON OF DONOR SITES IN THE UPPER AND LOWER LIMBS}

Ideally, donor nerves for free vascularized nerve transfer should exhibit a type A, B, or C pattern. ${ }^{[7]}$ Type A represents a nerve supplied segmentally by a long unbranching artery. Type $B$ is similar to type A except that the nerve divides early. Type $C$ is similar to type $A$, but the artery courses on the surface of the nerve instead of in parallel and gives several branches to the nerve that can subsequently be divided into multiple vascularized segments.

\section{Upper limb}

The study of Hong et al..$^{[1]}$ examined all nerves of the upper limb. They identified the following nerves as suitable for microsurgical transfer, being of type A or $\mathrm{C}$ : (1) the ulnar nerve in the upper arm and in the forearm; (2) the median nerve in the upper arm and in the forearm; (3) the segment of the anterior interosseous nerve distal to the flexor pollicis longus branch; (4) the upper lateral brachial nerve; (5) the lower lateral brachial nerve; (6) the superficial radial nerve; (7) the terminal branch of the posterior interosseous nerve; and (8) a branch to the extensor indicis following the posterior interosseous artery (when present). In normal clinical situations, nerves 1 and 2 cannot be used because of their functional importance. Harvest of nerve 3 results in loss of function of the pronator quadratus, which may be acceptable. This leaves nerves 4 through 8 as donor nerves for vascularized nerve transfer, and potentially nerve 3 in normal situations, with the superficial radial nerve being the longest with the most acceptable morbidity.

\section{Lower limb}

The study of Suami et al..$^{[81]}$ examined all nerves of the lower limb. They identified the following nerves: (1) the 
terminal cutaneous portion of the saphenous nerve; (2) the vastus lateralis branch of the femoral nerve; (3) the deep peroneal nerve distal to the extensor hallucis longus branch; (4) the posterior cutaneous nerve of the thigh; (5) the pudendal nerve; (6) the tibial nerve; (7) the lateral plantar nerve; (8) the medial plantar nerve; and (9) the sciatic nerve, with one of the profunda artery perforators. However, nerves 5-9 are not suitable for VNGs because of their short length or functional importance, unless an amputated limb or limb stump becomes available for harvesting of donor nerves. Consequently, nerves 1-4 are regarded as possible donor nerves. The deep peroneal nerve is the longest available with the least morbidity together with the sural nerve. The other versatile donor is the LFCN.

\section{Nonvascularized to vascularized wound bed}

Experimental studies have shown that in a normally vascularized bed, VNGs and NVNGs are equivalent for the treatment of short gaps of thin nerves. As suggested by Breidenbach and Terzis, ${ }^{[92]}$ a poorly vascularized bed can be transformed into a well-vascularized bed by flap transfer and a NVNG placed into it with similar results. This is a practice that resembles well-established flap transfers in heavily scarred beds for tendon gliding ${ }^{[93]}$ or scar-tethered nerves. ${ }^{[94]}$ Many free or local options exist, and an NVNG can then be used to bridge the gap. This technique can replace a VNG only when its sole indication is a poorly vascularized bed.

\section{HOW SHOULD WE CONSIDERTHE NERVE INCORPORATED IN A FLAP?}

Sensate or innervated flaps may provide a model for studying VNGs in the clinical setting. Innervated muscles show very efficient reinnervation even when radiated or placed in poorly vascularized beds. ${ }^{[95]}$ This is likely due to fact that a nerve included in a flap is in fact a VNG. Innervated flaps may be used to investigate the extent and speed of recovery of vascularized nerves transferred with flaps, either for reinnervation of the flap or to bridge composite defects that include nerves and soft tissues.

\section{CONCLUSION}

Whether it is worthwhile to perform a nerve graft and when remains controversial: VNGs do not have a real place in our reconstructive algorithm, resting in a limbo between 'grafts' and flaps. They are referred to as 'grafts' despite being vascularized, although by definition they possess a vascular pedicle and should be called 'flaps'.

Following this review, the authors conclude that VNGs do perform better than conventional nerve grafts by providing faster and better regeneration. However, this improvement in regeneration becomes relevant only in certain situation such as those shown in Table 1. The failure of several experimental studies to demonstrate an advantage may be due to lack of an appropriate model. No model to date has reproduced a long gap in a thick nerve which would mimic those likely to benefit from a VNG in humans.

Although VNGs can potentially significantly improve results, the major limitation is the lack of donor sites. VNGs perform best in long proximal gaps of large nerves, but harvesting such a large donor nerve is associated with significant morbidity. Although this may be partially be solved by the use of cable grafting, the donor nerves available still may not be sufficient, require multiple donor sites, complex procedures, and high morbidity.

\section{FUTURE DIRECTIONS}

Vascularized nerve allografts, which are associated with immunosuppression, a well-known facilitator of nerve regeneration, will likely become a useful tool in nerve reconstruction with VNGs. Coupling VNGs with NVNGs which surround them may be an option for larger nerves. Prefabricated nerve grafts may also play a role, as the delay in reconstruction caused by prefabrication may be compensated by improved regeneration.

\section{REFERENCES}

I. Phillipeaux JM, Vulpian A. Note on the trial of a lingual nerve trunk graft between two stumps of the hypoglossal. Arch Physiol Norm Pathol 1870;3:6I8.

2. Bunnell S, Boyes JH. Nerve grafts. Am J Surg 1939;44:64-75.

3. Klar E. About experiences and successes in application of plastic bridging defects in peripheral nerves. Z Neurol Psychiatr 1943; I76:533-55.

4. Seddon HJ. The use of autologous grafts for the repair of large gaps in peripheral nerves. BrJ Surg 1947;35:15I-67.

5. Tarlov IM, Epstein JA. Nerve grafts: the importance of an adequate blood supply. J Neurosurg 1945;2:49-71.

6. Strange FG. An operation for nerve pedicle grafting; preliminary communication. Br J Surg 1947;34:423-5.

7. Taylor GI, Ham FJ. The free vascularized nerve graft. Plast Reconstr Surg 1976;57:413-26.

8. Lind R, Wood MB. Comparison of pattern of early revascularisation of conventional versus vascularized nerve grafts in canine. J Reconstr Microsurg 1986;2:229-34.

9. Penkert G, Bini W, Samii M. Revascularization of nerve grafts: an experimental study. J Reconstr Microsurg 1988;4:319-25.

10. Sunderland S. Nerves and Nerve Injuries. 2nd ed. Edinburgh: Churchill Livingstone; 1978.

I I. Brooks D. The place of nerve-grafting in orthopedic surgery. J Bone Joint Surg Am 1955;37:299-305.

12. Seddon HJ. Nerve grafting. J Bone Joint Surg Br 1963;45:447-6I.

13. Best TJ, Mackinnon SE, Bain JR, Makino A, Evans PJ. Verification of a free vascularized nerve graft model in the rat with application to the peripheral nerve allograft. Plast Reconstr Surg 1993;92:516-25.

14. el-Barrany WG, Marei AG, Vallée B. Anatomic basis of vascularised nerve grafts: the blood supply of peripheral nerves. Surg Radiol Anat 1999;21:95-102.

15. Lux P, Breidenbach W, Firrel J. Determination of temporal changes in blood flow in vascularized and nonvascularized nerve grafts in the dog. Plast Reconstr Surg 1988;82:133-44.

16. Mani GV, Shurey C, Green CJ. Is early vascularization of nerve grafts necessary? J Hand Surg Br 1992; 17:536-43.

17. Settergren CR, Wood MB. Comparison of blood flow in free vascularized versus nonvascularized nerve grafts. J Reconstr Microsurg 1984;1:95-101.

18. Appenzeller O, Dhital KK, Cowen T, Burnstock G. The nerves to blood vessels supplying blood to nerves: the innervations of vasa nervorum. Brain Res 1984;304:383-6.

19. Cowen T, MacCormick DE, Toff WD, Burnstock G, Lumley JS. The effect of surgical procedures on blood vessel innervations. A fluorescence histochemical study of degeneration and regrowth of perivascular adrenergic nerves. Blood Vessels 1982;19:65-78. 
20. Selander D, Mansson LG, Karlsson L, Svanvik J. Adrenergic vasoconstriction in peripheral nerves of the rabbi. Anesthesiology 1985;62:6-10.

21. McCullough CJ, Grady O, Higgerson DW. Axon regeneration and vascularization of nerve grafts. An experimental study. B J Hand Surg Br 1984;9:323-7.

22. Seckel BR, Ryan SE, Simons JE, Gagne RG, Watkins E Jr. Vascularized versus nonvascularized nerve grafts: an experimental structural comparison. Plast Reconstr Surg 1986;78:21 I-20.

23. Pho RW, Lee YS, Rujiwetpongstorn V, Pang M. Histological studies of vascularised nerve graft and conventional nerve graft. J Hand Surg $\mathrm{Br}$ 1985; I:45-8.

24. Restepo Y, Merle M, Michon J, Folliguet B, Barrat E. Free vascularized nerve grafts: an experimental study in the rabbit. Microsurgery 1985;6:78-84.

25. Shibata M, Tsai TM, Firrel J, Breidenbach WC. Experimental comparison of vascularized and nonvascularized nerve grafting. J Hand Surg Am 1988;3:358-65.

26. Kanaya F, Firrel J, Tsai TM, Breidenbach WC. Functional results of vascularized versus nonvascularized nerve grafting. Plast Reconstr Surg 1992;5:924-30.

27. de Medinaceli L, Freed WJ, Wyatt RJ. An index of the functional condition of rat sciatic nerve based on measurements made from walking tracks. Exp Neurol 1982;77:634-43.

28. Kärcher $\mathrm{H}$, Kleinert $\mathrm{R}$. Regeneration in vascularized and free nerve grafts. A comparative morphological study in rats. J Maxillofac Surg 1986; I 4:34I-3.

29. Koshima I, Harii K. Experimental study of vascularized nerve grafts: multifactoral analyses of axonal regeneration of nerves transplanted into an acute burn wound. J Hand Surg Am 1985; 10:64-72.

30. Rose EH, Kowalski TA. Restoration of sensibility to anesthetic scarred digits with free vascularized nerve grafts from the dorsum of the foot. J Hand Surg Am 1985;4:5।4-21.

31. Doi K, Kuwata N, Kawakami F, Tamaru K, Kawai S. The free vascularized sural nerve graft. Microsurgery 1984;5: 175-84.

32. Doi K, Kuwata N, Sakai K, Tamaru K, Kawai S. A reliable technique of free vascularized sural nerve grafting and preliminary results of clinical applications. J Hand Surg Am 1987; 12:677-84.

33. Townsend PL, Taylor GI. Vascularised nerve grafts using composite arterialised neuro-venous systems. Br J Plast Surg 1984;37: I- 17.

34. Rose EH, Kowalski TA, Norris MS. The reversed venous arterialized nerve graft in digital nerve reconstruction across scarred beds. Plast Reconstr Surg 1989;83:593-604.

35. Bonney G, Birch R, Jamieson AM, Eames RA. Experience with vascularized nerve grafts. Clin Plast Surg 1984; I :137-42.

36. Ballance $C$, Duel $A B$. The operative treatment of facial palsy by the introduction of nerve grafts into the fallopian canal and by other intratemporal methods. Arch Otolaryngol 1932;15: I-70.

37. Baker DC, Conley J. Facial nerve grafting: a thirty year retrospective review. Clin Plast Surg 1979;6:343-60.

38. Kimata Y, Sakuraba M, Hishinuma S, Ebihara S, Hayashi R, Asakage T. Free vascularized nerve grafting for immediate facial nerve reconstruction. Laryngoscope 2005; I 15:331-6.

39. Koshima I, Yamamoto H, Moriguchi T, Kawada S, Ono Y. Combined anteroposterior tibial perforator-based flap with a vascularized deep peroneal nerve for repair of facial defect. Ann Plast Surg 1994;33:42I-5.

40. Koshima I, Nanba Y, Tsutsui T, Takahashi Y, Kawai A. Vascularized femoral nerve graft with anterolateral thigh true perforator flap for massive defects after cancer ablation in the upper arm. J Reconstr Microsurg 2003; 19:299-302.

4I. Koshima I, Nanba Y, Tsutsui T, Takahashi Y, Itoh S. New one-stage nerve pedicle grafting technique using the great auricular nerve for reconstruction of facial nerve defects. J Reconstr Microsurg 2004;20:357-6I.

42. Hasegawa T, Nakamura S, Manabe T, Mikawa Y. Vascularized nerve grafts for the treatment of large nerve gap after severe trauma to an upper extremity. Arch Orthop Trauma Surg 2004;214:209-13.

43. Lida T, Nakagawa M, Asano T, Fukushima C, Tachi K. Free vascularized lateral femoral cutaneous nerve graft with anterolateral thigh flap for reconstruction of facial nerve defects. J Reconstr Microsurg 2006;22:343-8.

44. House JW. Facial nerve grading systems. Laryngoscope 1983;93:1056-69.

45. Yanagihara N. On standardised documentation of facial palsy. Nihon Jibiinkoka Gakkai Kaiho 1977;80:799-805.

46. Kashiwa K, Kobayashi S, Ogino K, Kashiwaya G, Higuchi H. Inferolateral extension of the groin flap based on the artery accompanying the lateral femoral cutaneous nerve. J Reconstr Microsurg 2009;25:181-9.

47. Koshima L, Narushila M, Mihara M, Ushida G, Nakagawa M. Fascicular turnover flap for nerve gaps. J Plast Reconstr Aesthet Surg 2010;63:1008-14.

48. Schultes $\mathrm{G}$, Kärcher H, Gaggl A, Anderhuber F. Anatomic basis of vascularized nerve graft using the long thoracic nerve. Surg Radiol Anat 1999;21:91-4.
49. Kouyoumdjian JA. Peripheral nerve injuries: a retrospective survey of 456 cases. Muscle Nerve 2006;34:785-8.

50. Posch JL, dela Cruz-Saddul F. Nerve repair in trauma surgery: a ten-year study of 23I peripheral injuries. Orthop Rev 1980;9:35-45.

5I. Bruyns CN, Jaquet JB, Schreuders TA, Kalmijn S, Kuypers PD, Hovius SE. Predictors for return to work in patients with median and ulnar nerve injuries. J Hand Surg Am 2003;28:28-34.

52. Ruijs AC, Jaquet JB, Kalmijn S, Giele H, Hovius SE. Median and ulnar nerve injuries: a meta-analysis of predictors of motor and sensory recovery after modern microsurgical nerve repair. Plast Reconstr Surg 2005; I 6:484-94.

53. Vormdemvenne T, Langer M, Ochman S, Raschke M, Schult M. Long-term results after primary microsurgical repair of ulnar and median nerve injuries. A comparison of common score systems. Clin Neurol Neurosurg 2007; 109:263-71.

54. Allan $\mathrm{CH}$, Vanderhooft $\mathrm{E}$. Functional outcomes after nerve grafting. Atlas Hand Clin 2005; 10:93.

55. Jaquet JB, Luijsterburg AJ, Kalmijn S, Kuypers PD, Hofman A, Hovius SE. Median, ulnar, and combined median-ulnar nerve injuries: functional outcome and return to productivity. J Trauma 2001;51:687-92.

56. Gilbert A. Vascularized sural nerve graft. In: microreconstruction of Nerve Injuries. Philadelphia: WB Saunders; 1987. p. 576-60I.

57. Fachinelli $\mathrm{A}$, Masquelet $\mathrm{A}$, Restrepo J. The vascularized sural nerve. Int J Microsurg 1981;3:57-62.

58. Breidenbach W, Terzis JK. The anatomy of free vascularized nerve grafts. Clin Plast Surg 1984;1 I:65-7I.

59. Riordan CL, Nanney LB, Upton J 3rd, Wolfort SF. Vascularized medial sural cutaneous nerve based on the superficial sural artery: a reliable nerve graft. J Reconstr Microsurg 2002;18:147-52.

60. Zachary RB. Results of nerve suture. Spec Rep Ser Med Res Counc 1954:282:354-88

61. Gu YD, Wu MM, Zheng YL, Li HR, Xu YN. Arterialized venous free sural nerve grafting. Ann Plast Surg 1985;15:332-9.

62. Terzis JK, Kostopoulos VK. Vascularized nerve grafts and vascularized fascia for upper extremity nerve reconstruction. Hand (N Y) 2010;5:19-30.

63. Lebreton E, Bourgeon Y, Lascombes P, Merle M, Foucher G. Systemization of the vascularization of the ulnar nerve in its upper arm. Ann Chir Main 1983;2:2II-8.

64. Chuang DC, Epstein MD, Yeh MC, Wei FC. Functional restoration of elbow flexion in brachial plexus injuries: results in 167 patients (excluding obstetric brachial plexus injury). J Hand Surg Am 1993;|8:285-91.

65. Terzis JK, Kostopoulos VK.Vascularized ulnar nerve graft. $15 \mathrm{I}$ reconstructions for posttraumatic brachial plexus palsy. Plast Reconstr Surg 2009;| 23: 1276-9|

66. Terzis JK, Vekris MD, Soucacos PN. Outcomes of brachial plexus reconstruction in 204 patients with devastating paralysis. Plast Reconstr Surg 1999;5: I 22I-40.

67. Birch R, Dunckerton M, Bonney G, Jamieson AM. Experience with the free vascularized ulnar nerve graft in repair of supraclavicular lesions of the brachial plexus. Ciln Orthop Relat Res 1988;237:96-104.

68. Oberlin C, Alnot JY, Comtet JJ. Vascularized nerve trunk grafts. Technique and results of 27 cases. Ann Chir Main 1989;8:316-23.

69. Bertelli JA, Ghizoni MF. Results of $\mathrm{C} 5$ root grafting to the musculocutaneous nerve using pedicled, vascularized ulnar nerve grafts. J Hand Surg Am 2009;6:1821-6.

70. Okinaga $S$, Nagano A. Can vascularization improve the surgical outcome of the intercostal nerve transfer for traumatic brachial plexus palsy? A clinical comparison of vascularized and non-vascularized methods. Microsurgery 1999;19:176-180.

7I. Koshima L, Murashita T, Soeda S. Free vascularized deep peroneal neurocutaneous flap for repair of digital nerve defect involving severe finger damage. J Hand Surg Am 1991;16:227-9.

72. Willemart G, Kane A, Morrison WA. Island dorsalis pedis skin flap in combination with toe or toe segment transfer based on the same vascular pedicle. Plast Reconstr Surg 1999;104:1424-9.

73. Samson MC, Morris SF, Tweed AE. Dorsalis pedis flap donor site: acceptable or not? Plast Reconstr Surg 1998;102:1549-54.

74. Gilbert A. Composite tissue transfer from the foot: anatomic basis and surgical technique. In: Daniller Al, Strauch B, editors. Symposium on Microsurgery. St. Louis: CV Mosby; 1976. p. 230-42.

75. May JW Jr, Chait LA, Cohen BE, O'Brien BM. Free neurovascular flap from the first web of the foot in hand reconstructio. J Hand Surg Am 1977;2:387-93

76. del Pinal F, Garcia-Bernal FJ, Regalado J, Studer A, Cagigal A, Ayala A. The tibial second toe vascularized neurocutaneous free flap for major digital nerve defects. J Hand Surg Am 2007;32:209-17. 
77. Seddon HJ. Surgical Disorders of the Peripheral Nerves. Edinburgh: Churchill Livingstone; 1972.

78. Berry H, Richardson PM. Common peroneal nerve palsy: a clinical and electrophysiological review. J Neurol Neurosurg Psychiatry 1976;39: I 162-7।

79. Wood MB. Peroneal nerve repair. Surgical results. Clin Orthop Relat Res 1991;267:206-10.

80. Demuynck M, Zuker RM. The peroneal nerve: is repair worthwhile? J Reconstr Microsurg 1987;3:193-7.

8I. Suami H, Taylor GI, Pan WR. Angiosome territories of the nerves of the lower limbs. Plast Reconstr Surg 2003; I I2: 1790-8.

82. Terzis JK, Kostopoulos VK. Vascularized nerve grafts for lower extremety nerve reconstruction. Ann Plast Surg 2010;64:169-76.

83. Platt H, Lond MS. The classic. Traction lesions of the external popliteal nerve. By Harry Platt. 1940. Clin Orthop Relat Res 1986;210:5-8.

84. Kim DH, Kline DG. Management and results of peroneal nerve lesions. Neurosurgery 1996;39:312-9.

85. Kim DH, Murovic JA, Tiel RL, Kline DG. Management and outcomes in 318 operative common peroneal nerve lesions at the Louisiana State University Health Sciences Center. Neurosurgery 2004;54:142I-8.

86. Petit F, Minns AB, Dubernard JM, Hettieratchy S, Lee WP. Composite tissue allotransplantation and reconstructive surgery: first clinical applications. Ann Surg 2003;237:19-25.

87. Mackinnon SE, Doolabh VB, Novak CB, Trulock EP. Clinical outcome following nerve allograft transplantation. Plast Reconstr Surg 200 I; 107:1419-29.
88. Bain JR. Peripheral nerve and neuromuscular allotransplantation: current status. Microsurgery 2000;20:384-8.

89. Mackinnon SE, Hudson AR. Clinical application of peripheral nerve transplantation. Plast Reconstr Surg 1992;90:695-9.

90. Mackinnon SE. Nerve allotransplantation following severe tibial nerve injury. Case report. J Neurosurg 1996;84:67I-6.

91. Hong MK, Hong MK, Taylor GI. Angiosome territories of the nerves of the upper limbs. Plast Reconstr Surg 2006; I I 8: I 48-60.

92. Breidenbach WC, Terzis JK. Vascularized nerve grafts: an experimental and clinical review. Ann Plast Surg 1987; 18:137-46.

93. del Pinal F, Moraleda E, de Piero GH, Ruas JS. Outcomes of free adipofascial flaps combined with tenolysis in scarred beds. J Hand Surg Am 20 14;39:269-79.

94. Elliot D. Surgical management of painful peripheral nerves. Clin Plast Surg 20I4;41:589-6I3.

95. Cordova A, D'Arpa S, Moschella F. Gracilis free muscle transfer for morpho-functional reconstruction of the lower lip. Head Neck 2008;30:684-9.

How to cite this article: D'Arpa S, Claes KE, Stillaert F, Colebunders B, Monstrey S, Blondeel P. Vascularized nerve "grafts": just a graft or a worthwhile procedure?. Plast Aesthet Res 2015;2:183-94.

Source of Support: Nil, Conflict of Interest: None declared.

Received: 03-02-2015; Accepted: 20-05-2015 